\title{
IMUNIDADE À RUBÉOLA: INQUÉRITO SORO-EPIDEMIOLÓGICO EM HOSPITAL, ESTADO DE SÂO PAULO - BRASIL*
}

\author{
Alcyone Artioli Machado** \\ João Carlos da Costa** \\ Antonio Dorival Campos*
}

MACHADO, A.A. et al. Imunidade à rubéola: inquérito soro-epidemiológico em hospital, Estado de

São Paulo - Brasil. Rev. Saúde públ., S. Paulo, 22: 192 - 200, 1988.

RESUMO: Os títulos de anticorpos no soro pela reação de inibiçăo da hemaglutinação para rubéola, empregando o caulim para adsorçăo de beta-lipoproteínas bloqueadores inespecíficos, foram determinados em funcionárias do Hospital das Clínicas da Faculdade de Medicina de Ribeirão Preto da Universidade de Săo Paulo (Brasil), no periodo de 1982-1983 e confrontados com idade, cor, unidade hospitalar, local, cargo, tempo de emprego, antecedentes de rubéola ou comunicante na vigência ou não de gravidez. Participaram do estudo 1.886 funcionárias $(88,9 \%$ de 2.121$)$ tendo títulos com a distribuiçăo: $9,6 \%<10,1,3 \%-10,3,5 \%-20,5,8 \%-40,10,6 \%-80,20,7 \%-160,27,8 \%-320,12,6 \%-640,7,3 \%$ 1.280 e $0,8 \%-2.560$. Houve fraca associaçāo entre títulos e quaisquer das variáveis de confrontaçāo $(\mathrm{P} \equiv$ 0); $87,1 \%$ das funcionárias negaram antecedentes de rubeola e destas $73,9 \%$ tiveram títulos > 20; $57,6 \%$ negaram ser comunicantes e apresentaram títulos $\geq 20$; em 1,1\% que referiram história de rubéola, os títulos foram $\leq 20 ; 97 \%$ negaram contacto com rubeola durante a gravidez. Houve somente um caso de malformação congênita após rubéola no primeiro trimestre da gravidez. Das 351 funcionárias sãs, e com títulos $\geq 640$, em $9,4 \%$ demonstrou-se IgM específica. Não foi notada flutuação significativa dos títulos em diferentes amostras em periodo de observação de até um ano. Conclui-se que a maioria das funcionárias é imune à rubéola (título > 20) independente de quaisquer parâmetros analisados; a presença de IgM específica em algumas funcionárias pode ser compatível com doença subclínica. Este inquérito foi considerado útil na orientação de funcionárias grávidas comunicantes de caso suspeito ou confirmado de rubeola, e para as não-grávidas e não-imunes a indicaçăo da profilaxia pela vacina.

UNITERMOS: Rubéola, imunologia. Inquéritos epidemiologicos. Sorodiagnóstico.

\section{INTRODUÇÃO}

A rubéola ocupa um lugar de destaque quanto à freqüência de morbidade de infecção intraútero, assim como a lues, toxoplasmose e citomegalia.

Ao risco de adquirir rubéola durante a gravidez, e com ela o nascimento de crianças com embriopatia, estão expostas somente as mães que năo têm no soro anticorpos anti-vírus da rubéola.

Aproximadamente $80 \%$ dos americanos desenvolvem anticorpos contra o vírus da rubéola até atingir 20 anos de idade ${ }^{37}$. No Brasil, Veronesi e col. ${ }^{48}$ encontraram $80 \%$ de adultos imunes à rubéola na população estudada. Ishak e col. ${ }^{24}$, em Goiânia - GO, mostraram que $15,5 \%$ da população feminina entre 20 e 30 anos de idade entram em período gestacional sem apresentar an- ticorpos (inibidores de hemaglutinação) para vírus da rubéola, constituindo um grupo de risco quanto à infecçăo congênita.

A presunção de que indivíduos ligados à área da saúde são menos suscetíveis à rubéola que a população geral, não é corroborada por estudos sorológicos realizados em hospitais. Como acontece com a população geral, 10 a $20 \%$ do pessoal de hospital não possuem anticorpo detectável para rubéola, e uma boa proporção é de mulheres jovens em idade fértil ${ }^{20} 50$. A literatura é repleta de casos de exposiçăo de pacientes grávidas a contágio com pessoal médico e paramédico portador de rubéol ${ }^{13,29}$. Polk e col. ${ }^{36}$ enfatizam a necessidade de triagem sorológica para rubéola em empregados de hospitais. O "U.S. Public Health Service Advisory Committee on Immunization Service"14 recomenda a vacinação de todo servidor de hospital, suscetivel à rubéola, que possa vir a transmitr-la a pacientes grávidas.

\footnotetext{
* Apresentado no XX Congresso da Sociedade Brasileira de Medicina Tropical, 1984, Salvador, BA - Brasil.

*. Faculdade de Medicina de Ribeirão Preto da Universidade de Såo Paulo - Av. Bandeirantes, 3900 - 14049 - Ribeirão Preto, SP - Brasil.
} 
Na sorologia para rubéola, a reação de inibição de hemaglutinaçăo $(\mathrm{RIH})^{13}$ é a de uso mais generalizado tanto para diagnóstico clínico como em inquéritos, devido a boa sensibilidade e fácil execuçăo ${ }^{10,11,12,35,48}$. A complementaçăo do método quanto à pesquisa de imunoglobulina $\mathrm{M}$ (IgM) específica destaca-se em demonstrar a infecção primária ${ }^{3,25}$.

O Hospital das Clínicas da Faculdade de Medicina de Ribeirão Preto - USP (HCFMRP-USP) conta com grande número de funcionárias que, na maioria das vezes desconhecem seu estado imunitário em relaçăo à rubéola.

No presente inquérito soro-epidemiológico propoe-se:

1- Verificar pela RIH o estado imunitário das funcionárias do HCFMRP-USP e, conseqüentemente, triar a populaçăo suscetível, no perfodo de 1982-1983.

2- Correlacionar os resultados das dosagens com idade, setor de trabalho, cargo, tempo de emprego, antecedentes de rubéola ou de comunicante na vigência ou nåo de gravidez, vacinaçăo contra rubéla e gestaçőes.

\section{CASUISTICA E MÉTODOS}

No período de 1982-1983 estavam registradas no HCFMRP-USP, 2.121 funcionárias. Destas, $1.886(88,9 \%)$ participaram do inquérito soroepidemiologico. Em primeiro lugar, foram submetidas a um questionário onde constavam itens para coleta de informaçóes sobre idade, cor, cargo e setor de trabalho, tempo de emprego, tempo de antecedentes ou comunicante antirubéola em período de gravidez ou năo, vacinaçăo anti-rubéola e gestaçōes (número, aborto, malformaçăo congênita). Para a pesquisa no soro de anticorpos anti-vírus da rubéola pela RIH, de todas 1.886 funcionárias foi colhida uma amostra de sangue; em 55 (2,92\%) retirou-se mais de uma amostra, num peíodo que variou de 50 a 385 dias após a primeira, para estudo da evoluçăo de títulos de anticorpos; em 351 (18,6\%) que apresentaram títulos de anticorpos maiores ou iguais a 640, os respectivos soros foram tratados pelo 2mercaptoetanol (2-ME) ${ }^{3}$, para pesquisa de imunoglobulina $M$ específica; em 8 funcionárias com suspeita de rubéola e um comunicante de rubéola, durante período de gravidez, coletaram-se duas amostras de sangue com intervalo de 15 a 20 dias entre elas, e eventualmente uma terceira amostra, para confirmaçăo de diagnóstico.

O soro obtido foi armazenado a $-20^{\circ} \mathrm{C}$ por período que năo excedeu a 10 meses antes da realizaçăo da RIH.

A pesquisa de anticorpos no soro através da
RIH baseou-se no método de Stewart e col. ${ }^{43}$ adaptado para microtécnica e com pequenas modificaçōes ${ }^{7}$. Utilizaram-se hemácias de pinto de um dia como suporte; caulim (Kaolin-JT Baker, EUA lote 741395 ) a $25 \%$ em tampão borato, para remoção de inibidores inespecíficos segundo a técnica de Clarke e Casals 15 ; antígeno hemaglutinante do vírus da rubéola (BioMérieux); demais reagentes (diluentes) preparados no próprio laboratório: tampåo estéril "BABS" (Bovalbumin-Borate Saline) $\mathrm{pH} 9,0$, tampão fosfato $\mathrm{pH}$ rigorosamente 6,2 , soluçăo de Alsever estéril pH entre 5,9 a 6,05. Soros padrőes positivo e negativo (Bio-Mérieux), separados em alíquotas de $0,1 \mathrm{ml}$ e armazenados a $-20^{\circ} \mathrm{C}$ até o inomento das dosagens, foram utilizados como controles da reação.

Para maior segurança, em fase de pré-testes, decidiu-se observar o poder adsorvente do caulim em uso, para remoção de inibidores inespecificos, que estão nas fraçбes das lipo-proteínas, e podem ser responsáveis por reaçōes falsopositivas. Em 6 amostras de soro foram determinados os níveis de lipoproteínas de muito baixa, baixa e alta densidades (VLDL, LDL e HDL) antes e após tratamento com o caulim. Do mesmo modo, como o caulim pode adsorver simultaneamente IgG e IgM do soro, e assim eventualmente alterar os títulos de anticorpos para rubéola, em 27 amostras de soro, dosaram-se através de imunodifusăo radial simples utilizando imunoplacas preparadas no próprio laborat6rio, segundo Barreto 4 , os níveis destas imunoglobulinas antes e apos o tratamento com o caulim.

Visando opção para hemácias de ave, 226 soros foram testados pela RIH simultaneamente com hemácias de ganso e pinto de um dia.

A análise estatística foi realizada através da análise exploratória dos dados pelo teste de Wil$\operatorname{coxon}^{21}$ e Spearman ${ }^{41}$. A correlação entre os títulos de anticorpos totais pela RIH e os dados epidemiológicos (à exceçăo de cor e antecedentes) do questionário foi feita pela codificaçăo dos dados e aplicaçăo de pacotes estatísticos "Biomedical Computer P-series (BMDP)" e "Statistical Analysis System (SAS)", no Departamento de Estatística e Computaçăo da Universidade Federal de Săo Carlos. O valor verdadeiro da medida de associação fraca ou forte com base nos dados dispostos em tabelas uni e bidimensionais foi determinado pelo coeficiente de Pearson $(P)^{8}$ onde $P \cong 0$ significa associação fraca e $P \cong 1$ associaçăo forte.

\section{RESULTADOS E DISCUSSÃO}

Em uma primeira fase deste estudo procedeuse à avaliaçăo da técnica da RIH, visto que a con- 
fiabilidade aos resultados obtidos dependia do controle das diferentes variáveis.

Assim, demonstrou-se que o lote de caulim utilizado em todo o estudo removeu efetivamente as lipoproteínas, uma vez que em 6 soros testados após tratamento não se constatou presença de nenhuma quantidade de lipoproteínas de alta, baixa e muito baixa densidade.

Outro inconveniente seria a ação do caulim sobre as imunoglobulinas do soro particularmente $\operatorname{IgM}^{10,26}$. Encontrou-se uma redução de apenas $7 \%$ para IgG, fato também observado por outros autores ${ }^{46}$, e de $65 \%$ para IgM. O método que usa o caulim foi considerado adequado para proceder este inquérito sorologico, uma vez que pouco interferiu nos teores de IgG dos soros.

Quanto à pesquisa de opçăo para hemácias de ave, com os títulos obtidos pela RIH em 226 soros testados simultaneamente com hemácias de pinto de um dia e de ganso, foi construída uma curva de discrepância relativa que se apresentou simétrica evidenciando, portanto, que a RIH pode ser realizada com os dois tipos de hemácias. Além disso, o teste não paramétrico de Wilcoxon demonstrou também que os resultados são concordantes.

As dosagens na RIH foram feitas empregandose hemácias de pinto por medida econômica, pois com hemácias de ganso notou-se que seria necessário dispender uma maior quantidade de antígeno hemaglutinante do vírus da rubéola.

Quanto ao título mínimo imune, Bradstreet e col. $^{9}$ definiram como aceitável um título maior que 20 como compatível com imunidade à rubéola, que na escala de diluiçoes duplas do método é a partir do título 40 . Veronesi e col. ${ }^{47}$, estudando crianças de 3 a 15 anos, concluíram que o título de 20 na RIH para rubéola deve traduzir mais freqüentemente suscetibilidade do que imunidade.

Na literatura são descritos vários casos de mulheres com documentado título 10 para $\mathrm{RIH}$ para rubéola, consideradas imunes, que no entanto em gravidezes subseqüentes apresentaram evidência clínica e sorológica de rubéola ${ }^{6,33}$. No presente estudo foram consideradas imunes as funcionárias com títulos maiores que 20 .

Outro fator a considerar são os indivíduos com baixos títulos de anticorpos, por exemplo 40, 80 , que estariam sujeitos à reinfecção $0^{1739}$. A ocorrênciá ou não de viremia nesses casos é ainda polêmica ${ }^{27,39}$.

Reinfecçăo é usualmente assintomática e diagnosticada sorologicamente por aumento (maior ou igual a 4 vezes) no título de anticorpos para rubéola quando o paciente é investigado após uma história de contacto com doença exantemática. Tem sido aceito que reinfecção é distingüida sorologicamente de doença subclínica pela presença de anticorpos para rubéola em período anterior à atual exposiçăo ou pela ausência, mesmo em baixo nível, de IgM específica anti-vírus da rubéola no soro coletado em ocasiōes oportunas ${ }^{16}$.

Sabe-se que para haver dano fetal é necessária a viremia. Davis e col. ${ }^{17}$, estudando crianças vacinadas, reexpostas ao vírus da rubéola, demonstraram que elas não apresentaram viremia. Já outros autores ${ }^{31}$ descrevem que IgM específica pode ser encontrada em reinfecçăo quando houve soroconversão por infecção natural. Outros acreditam que a IgM específica anti-vírus da rubéola é mais comumente encontrada após reinfecção em vacinados ${ }^{16,32}$. $O$ assunto permanece controvertido.

Das 1.886 funcionárias, $1.617(85,7 \%)$ tiveram títulos pela $\mathrm{RIH}>20$ e foram consideradas imunes, e $14,3 \%$ com títulos $\leq 20$ portanto suscetíveis. Estes dados aproximam-se dos obtidos por autores nacionais em outras populaçð̄es ${ }^{1,45,47}$, mas diferem de outros, provavelmente pela diferença do método usado ou classificação de título imune/não imune ${ }^{2,11}$. Da mesma forma, a comparação com os resultados obtidos em outros países, os deste estudo foram concordantes ${ }^{18,38}$ ou diferentes ${ }^{30}$. A taxa de imunidade à rubéola pode ser variável de acordo com a área geográfica, o tipo de população estudada, o método empregado, e com o título imune considerado.

Surtos de rubéola em hospitais têm causado transtornos como falta ao trabalho, aborto eletivo, ansiedades, fechamento de enfermarias e publicidade adversa para os hospitais envolvi$\operatorname{dos}^{13,29,36,44}$.

Estudos realizados com estudantes de medicina, de enfermagem e com funcionários, em diferentes hospitais, têm encontrado percentagens de $22 \%$ a $36 \%$ quanto a suscetíveis para rubéola $^{13,29,34,36}$.

$\mathrm{Na}$ Figura encontra-se a distribuição dos títulos de anticorpos para rubéola nas 1.886 funcionárias onde os mais freqüentes são 160 e 320.

A Tabela 1 mostra a distribuição dos títulos de anticorpos segundo a faixa etária: $80 \%$ das funcionárias estão na faixa dos 20 aos 40 anos e destas $12,1 \%$ não são imunes à rubéola, constituindo a populaçăo de risco de ocorrência de rubéola congênita. Qualquer título de anticorpo é encontrado em qualquer faixa etária com exceção do título 20 para mulheres com idade $\geq 50$ anos e do título 2.560 para mulheres na faixa etária dos 40 aos 49 anos. Pelo encontro de um coeficiente de Pearson de 0,144 conclui-se não haver correlação de título 
de anticorpo com a idade. Este fato já foi registrado por outros autores em estudos com diferentes populaçסes ${ }^{30,12}$.

Não foi possível analisar o dado cor, pois $78,6 \%$ da população em estudo eram de cor branca.

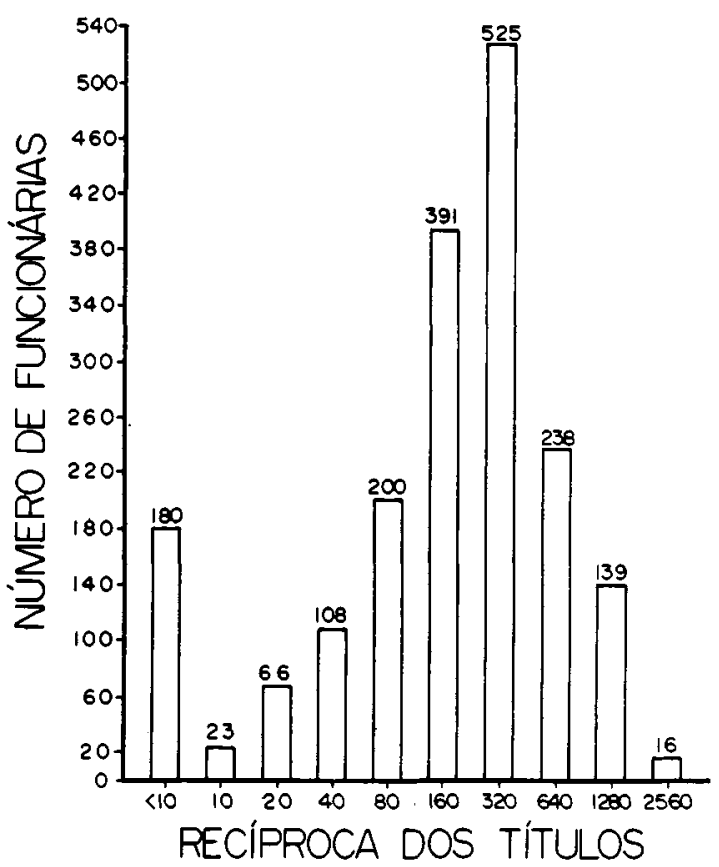

Figura - Recíproca dos titulos de anticorpos na RIH para rubéola empregando-se hemáclas de pinto, no soro de 1.886 funcionárias do HCFMRP-USP (1982-1983).
A análise dos títulos de anticorpos com os diferentes núcleos de trabalho dos funcionários (Tabela 2) mostrou que há baixa associaçăo entre as variáveis analisadas $(P=0,073)$. A finalidade da divisão dos títulos em faixa foi para as funcionárias com títulos que não dăo imunidade ou săo baixos, e conseqüentemente correriam maior risco de infeç̧ão ou eventualmente a reinfecção pelo vírus da rubéola.

Estudando-se os setores separadamente obteve-se uma taxa de suscetiveis de $10 \%$ a $36 \%$ nos diferentes locais, semelhante ao descrito na literatura $34,4,48$.

Justifica-se o encontro de 45 funcionárias que não informaram sobre o núcleo de atividade porque estavam em periodo de admissåo. Notase, entretanto, que em sua maioria eram imunes.

O estudo revelou que o título de anticorpos para rubéola parece ser independente do local de trabalho e do cargo ocupado. Reforça este fato o encontro de não suscetíveis em ambientes fechados ou isolados do HCFMRP-USP - Campus, a exemplo dos setores de Hemodinâmica e do Centro de Informaçăo e Análise, onde há pouco, ou nenhum contacto com pacientes. A correlação dos títulos com tempo de serviço revelou o coeficiente $P=0,155$ (Tabela 3). Nos setores onde haveria preocupação em casos de surtos de rubéola (Ginecologia e Obstetrícia, Pediatria, Moléstias Infecciosas), ocorreu baixa percentagem de funcionárias não-imunes.

A informação da história pregressa da rubéola, assim como a história de contacto e a respectiva confrontaçăo com títulos de anticorpos encontram-se nas Tabelas 4 e 5 . Notam-se que $87,1 \%$

\section{TABELA 1}

Reação de inibição de hemaglutinação para rubéola: recíproca dos tútulos de anticorpos no soro e faixa etária de funcionários do Hospital das Clínicas da Faculdade de Medicina de Ribeirão Preto, USP, 1982 - 1983.

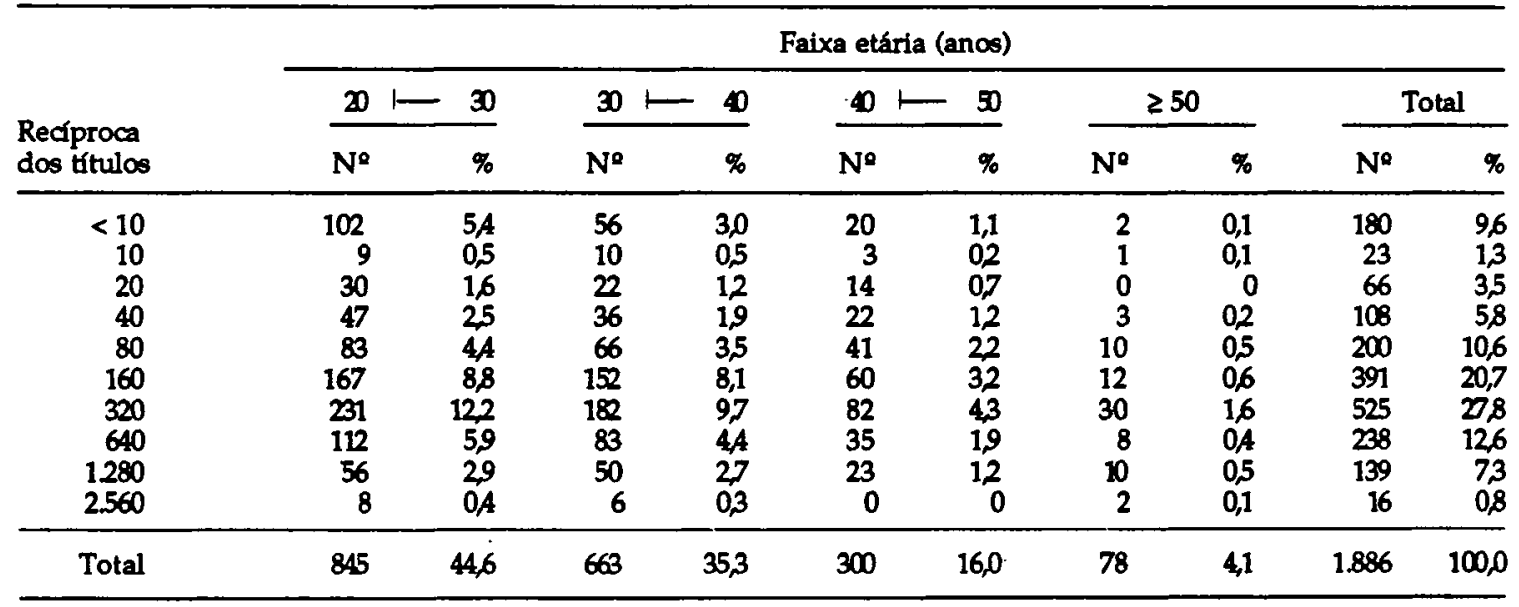

Coeficiente de Pearson $=0,144$. 


\section{TABELA 2}

Reaçăo de inibição de hemaglutinação para a rubeola: recíproca dos títulos de anticorpos no soro e unidade de trabalho de funcionários do Hospital das Clínicas da Faculdade de Medicina de Ribeirão Preto, USP, 1982 - 1983.

\begin{tabular}{|c|c|c|c|c|c|c|c|c|c|c|c|c|}
\hline \multirow{2}{*}{$\begin{array}{l}\text { Recíproca dos } \\
\text { títulos de anti- } \\
\text { corpos }\end{array}$} & \multicolumn{2}{|c|}{$\begin{array}{c}\text { Hospital das } \\
\text { Clínicas } \\
\text { Campus }\end{array}$} & \multicolumn{2}{|c|}{$\begin{array}{l}\text { Hospital das } \\
\text { Clínicas } \\
\text { Cidade }\end{array}$} & \multicolumn{2}{|c|}{$\begin{array}{c}\text { Centro Saúde } \\
\text { Escola } \\
\text { Vila Lobato }\end{array}$} & \multicolumn{2}{|c|}{$\begin{array}{l}\text { Hospital } \\
\text { dia }\end{array}$} & \multicolumn{2}{|c|}{$\begin{array}{c}\text { Sem } \\
\text { Informação }\end{array}$} & \multicolumn{2}{|c|}{ Total } \\
\hline & $\mathrm{N}^{2}$ & $\%$ & No & $\%$ & No & $\%$ & $\mathrm{~N}^{2}$ & $\%$ & $\mathrm{~N}^{\mathrm{e}}$ & $\%$ & $N^{2}$ & $\%$ \\
\hline $\begin{array}{c}<10 \longmapsto 40 \\
40 \longmapsto 160 \\
160 \longmapsto 640 \\
\geq 640\end{array}$ & $\begin{array}{l}235 \\
266 \\
793 \\
337\end{array}$ & $\begin{array}{l}12,5 \\
14,1 \\
42,0 \\
17,9\end{array}$ & $\begin{array}{l}20 \\
34 \\
88 \\
45\end{array}$ & $\begin{array}{l}1,1 \\
1,8 \\
4,6 \\
24\end{array}$ & $\begin{array}{l}5 \\
2 \\
5 \\
2\end{array}$ & $\begin{array}{l}0,3 \\
0,1 \\
0,3 \\
0,1\end{array}$ & $\begin{array}{l}1 \\
1 \\
6 \\
1\end{array}$ & $\begin{array}{l}0,1 \\
0,1 \\
0,2 \\
0,1\end{array}$ & $\begin{array}{r}8 \\
5 \\
24 \\
8\end{array}$ & $\begin{array}{l}0,4 \\
0,3 \\
1,3 \\
0,4\end{array}$ & $\begin{array}{l}269 \\
308 \\
916 \\
393\end{array}$ & $\begin{array}{l}14,3 \\
16,4 \\
48,4 \\
20,9\end{array}$ \\
\hline Total & 1.631 & 86,5 & 187 & 9,9 & 14 & 0,8 & 9 & 0,5 & 45 & 2,4 & 1.886 & 100,0 \\
\hline
\end{tabular}

Coeficiente de Pearson $=0,073$

TABELA 3

Reação de inibição da hemaglutinação para rubéola: reciproca dos títulos de anticorpos no soro e tempo de serviço de funcionárias do Hospital das Clínicas da Faculdade de Medicina de Ribeirão Preto, USP, 1982 - 1983.

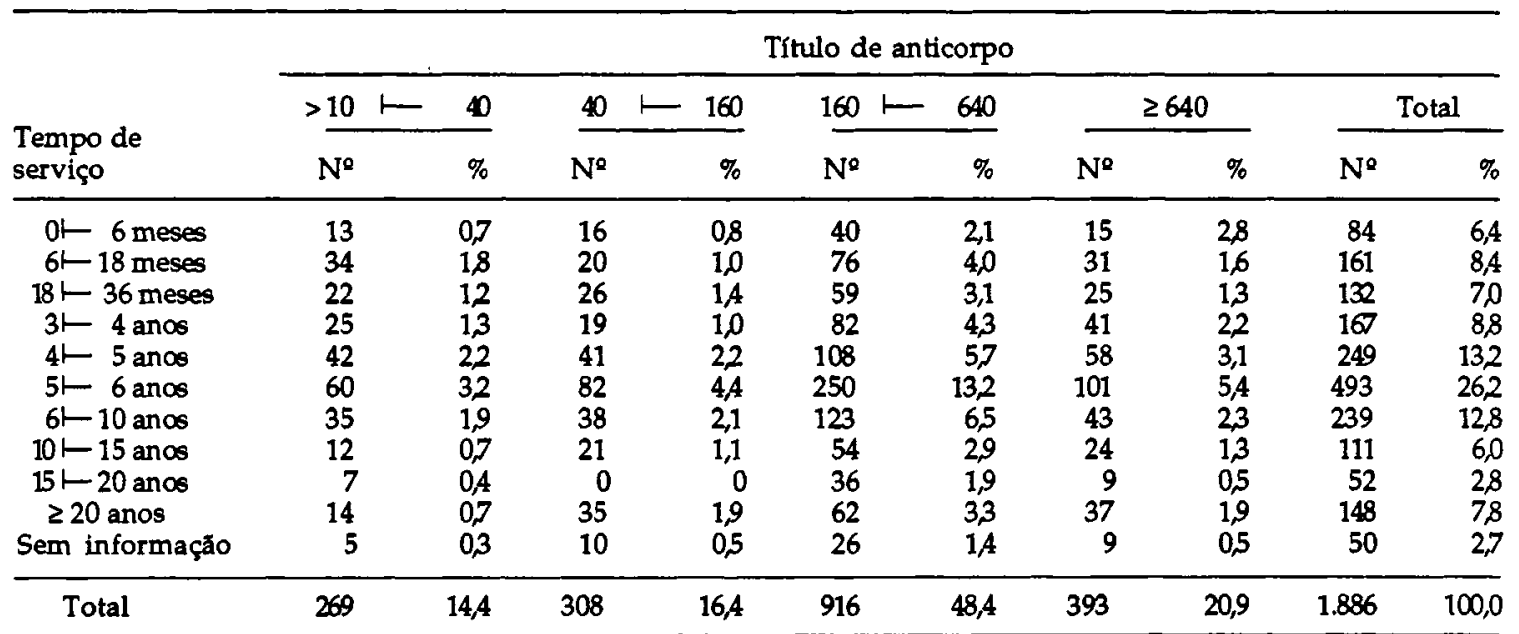

$\mathrm{P}=0,155$

TABELA 4

Reação de inibição de hemaglutinaçāo para rubéola: recíproca dos títulos de anticorpos em valores maiores e menores ou iguais a 20 no soro e antecedentes de rubéola, de funcionárias do Hospital das Clínicas da Faculdade de Medicina de Ribeirão Preto, USP, 1982 - 1983.

\begin{tabular}{|c|c|c|c|c|c|c|}
\hline \multirow{3}{*}{$\begin{array}{l}\text { Provável } \\
\text { antecedente } \\
\text { de rubéola }\end{array}$} & \multicolumn{6}{|c|}{ Títulos de anticorpos } \\
\hline & \multicolumn{2}{|c|}{$>20$} & \multicolumn{2}{|c|}{$\leq 20$} & \multicolumn{2}{|c|}{ Total } \\
\hline & $\mathrm{N}^{\mathbf{2}}$ & $\%$ & $N^{2}$ & $\%$ & $N^{2}$ & $\%$ \\
\hline $\begin{array}{l}\text { Presente } \\
\text { Ausente } \\
\text { Não }\end{array}$ & $\begin{array}{r}187 \\
1.394\end{array}$ & $\begin{array}{r}9,9 \\
73,9\end{array}$ & $\begin{array}{r}21 \\
248\end{array}$ & $\begin{array}{r}1,1 \\
13,1\end{array}$ & $\begin{array}{r}208 \\
1.642\end{array}$ & $\begin{array}{l}11,0 \\
87,1\end{array}$ \\
\hline $\begin{array}{l}\text { informado } \\
\text { Ignorado }\end{array}$ & $\begin{array}{l}12 \\
24\end{array}$ & $\begin{array}{l}0,6 \\
1,3\end{array}$ & $\begin{array}{l}0 \\
0\end{array}$ & $\begin{array}{l}0 \\
0\end{array}$ & $\begin{array}{l}12 \\
24\end{array}$ & $\begin{array}{l}0,6 \\
1,3\end{array}$ \\
\hline Total & 1.617 & 85,7 & 269 & 14,3 & 1.886 & 100,0 \\
\hline
\end{tabular}

\section{TABELA 5}

Reação de inibição de hemaglutinação para rubéola: recíproca dos títulos de anticorpos em diluiçōes maiores e menores ou iguais a 20 no soro e antecedentes de contacto com rubéola, de funcionárias do Hospital das Clínicas da Faculdade de Medicina de Ribeirão Preto, USP, 1982 - 1983.

\begin{tabular}{|c|c|c|c|c|c|c|}
\hline \multirow{3}{*}{$\begin{array}{l}\text { Provável } \\
\text { antecedente } \\
\text { de contacto }\end{array}$} & \multicolumn{6}{|c|}{ Títulos de anticorpos } \\
\hline & \multicolumn{2}{|c|}{$>20$} & \multicolumn{2}{|c|}{$\leq 20$} & \multicolumn{2}{|c|}{ Total } \\
\hline & $\mathrm{N}^{2}$ & $\%$ & $\mathrm{~N}^{2}$ & $\%$ & $\mathrm{~N}^{\circ}$ & $\%$ \\
\hline $\begin{array}{l}\text { Presente } \\
\text { Ausente } \\
\text { Não }\end{array}$ & $\begin{array}{r}336 \\
1.086\end{array}$ & $\begin{array}{l}17,8 \\
57,6\end{array}$ & $\begin{array}{r}59 \\
184\end{array}$ & $\begin{array}{l}3,1 \\
9,8\end{array}$ & $\begin{array}{r}395 \\
1.270\end{array}$ & $\begin{array}{l}20,9 \\
67,4\end{array}$ \\
\hline $\begin{array}{l}\text { informado } \\
\text { Ignorado }\end{array}$ & $\begin{array}{r}12 \\
183\end{array}$ & $\begin{array}{l}0,6 \\
9,7\end{array}$ & $\begin{array}{r}0 \\
26\end{array}$ & $\begin{array}{r}0 \\
1,4\end{array}$ & $\begin{array}{r}12 \\
209\end{array}$ & $\begin{array}{r}0,6 \\
11,1\end{array}$ \\
\hline Total & 1.617 & 85,7 & 269 & 14,3 & 1.886 & 100,0 \\
\hline
\end{tabular}


das funcionárias negaram história de rubéola e destas, $73,9 \%$, foram consideradas imunes. $\mathrm{Na}$ quelas com história de rubéola, apenas $1,1 \%$ não eram imunes.

Mesmo as funcionárias que ignoravam este antecedente ou não o informavam, possuíam títulos que conferem imunidade. Quanto aos antecedentes de contacto com rubéola e o estado imunitário (Tabela 5) nota-se que $67,4 \%$ negaram, sendo que $57,6 \%$ tinham títulos $>20$. Das que afirmaram, 3,1\% não eram imunes.

Para verificar se havia funcionárias com infecção em fase recente pesquisou-se anticorpos das classe IgM anti-vírus da rubéola em 351 funcionárias, selecionadas por apresentarem títulos de anticorpos $\geq 640$, e sem história prévia de rubéola. Apesar da baixa sensibilidade do método com o $2-\mathrm{ME}^{44}$ era o disponível na ocasião, pouco dispendioso e de fácil manejo ${ }^{3}$.

Na Tabela 6 notam-se que $9,4 \%$ dos soros testados sofreram queda, nos títulos, de 4 vezes após o tratamento com o 2-ME. Ressalta-se que o tratamento dos soros pelos caulim provocou a adsorção de $\operatorname{IgM}$ em $65 \%$.

De acordo com vários investigadores ${ }^{22,25}$ a $\operatorname{IgM}$ específica para rubéola pode estar presente 4 a 5 semanas após a fase aguda de doença pós-natal. Alguns relatam sua presença até 3 meses após a fase aguda da doença ${ }^{40}$. São conhecidos na literatura casos de persistência de $\operatorname{IgM~2,4}$ até 52 meses do quadro agudo de rubéola adquirida durante a gravide $^{19,28,42}$, tendo como provável explicação o estímulo fetal ao sistema imunológico materno ${ }^{5}$.

As funcionárias cujos soros foram estudados pelo 2-ME negaram rubéola na gravidez, podendo-se supor que poderiam ter tido infecção recente sob a forma subclínica da doença. Fica difícil estabelecer se tiveram rubéola no passado remoto ou recente. Outra hipótese seria a de erro técnico, com presença de resultado falso-positivo. Todavia alguns autores referem bons resultados com 2-ME salientando a baixa existência de falsopositivo ${ }^{44}$. A situação se complicaria caso alguma dessas funcionárias estivessem grávidas ou viessem a engravidar. A interpretação de resultados em termos de provável tempo de rubéola pode ser errônea, uma vez que a IgM específica pode persistir por períodos de tempo curtos ou longos após a infecção.

A evolução dos títulos foi estudada em 55 funcionárias. Como foi observado por outros autores ${ }^{49}$, aqui também foi demonstrado que os títulos de anticorpos para rubéola pela RIH não sofrem flutuaçăo significativa com o tempo.

Títulos iguais ou maiores do que 320 foram observados nas 8 funcionárias que apresentaram

\section{TABELA 6}

Reação de inibição de hemaglutinação para rubéola: variação dos títulos de anticorpos após tratamento com 2-mercaptoetanol (2-ME) em 351 soros de funcionárias do Hospital das Clínicas da Faculdade de Medicina de Ribeirão Preto, USP, 1982 - 1983.

\begin{tabular}{lcc}
\hline Variação do título após 2-ME & Freqüência & $\%$ \\
\hline Ausente & 154 & 43,9 \\
De \pm 1 diluição & 162 & 46,1 \\
Igual ou maior a 2 diluições & 33 & 9,4 \\
Inconclusível & 2 & 0,6 \\
\hline Total & 351 & 100,0 \\
\hline
\end{tabular}

quadro clínico suspeito de rubéola. Destas, em 3 demonstrou-se a soroconversão através de duas amostras de sangue com intervalo de 20 dias por ocasião da doença e convalescença, e em 5 a sorologia negativa já era conhecida alguns meses antes do aparecimento da doença. Em funcionária, em período de gravidez, que teve contacto com paciente portador de rubéola, o teste mostrou sorologia negativa em duas amostras de sangue com intervalo de 15 dias colhidas nesta fase e em uma terceira um ano após a primeira.

Em outras duas funcionárias também foi detectada a soroconversăo, mas elas negaram quadro viral. Não fizeram parte do grupo acima descrito ou do estudo de flutuação de título. 0 intervalo entre as amostras foi de 9 meses, e o título de anticorpos era $<10$ e passou a 640 . A forma subclínica da rubéola tem importância no caso de mulheres em estado inicial de gravide ${ }^{23}$.

Não se pode estabelecer taxa de rubéola subclínica na população estudada devido ao pequeno número de casos.

Entende-se ser de grande valia o estabelecimento do estado imunitário para rubéola em mulheres em idade fértil, em especial nas que trabalham em ambiente hospitalar. Salienta-se que a triagem sorológica para rubéola, com os conhecimentos das suscetíveis no ambiente hospitalar, propicia melhor adequação da conduta médica para as comunicantes de rubéola fora ou durante período de gravidez.

\section{CONCLUSÕES}

1 - A maioria $(85,7 \%)$ das funcionárias do HCFMRP-USP no período de 1982-1983, possui nível protetor de anticorpos para a rubéola.

2 - Os títulos de anticorpos para rubéola não apresentaram correlação com idade, setor e tipo de trabalho e tempo de serviço. Devido a 
predominância da cor branca na população estudada, a correlaçăo com esse parâmetro ficou prejudicada.

3 - Os títulos de anticorpos em periodo de observaçăo de até um ano em um grupo de funcionárias năo mostrou flutuaçăo significativa.

\section{4 - A presença de IgM específica para rubéla}

em algumas funcionárias assintomáticas, evidenciou a possibilidade de doença subclínica.

5 - Este inquérito soro-epidemiológico foi considerado útil na orientação quanto ao estado imunitário de funcionárias grávidas comunicantes de caso suspeito ou confirmado de rubéola, bem como para indicaçăo de profilaxia por vacina nas suscetíveis.

MACHADO, A.A. et al. [Immunity to rubella: a serological-epidemiological survey in female hospital employees, S. Paulo State, Brazil. Rev. Saúde públ., S. Paulo, 22: 192 - 200, 1988.

ABSTRACT: Antibody titers to rubella were determined by the hemagglutination inhibition test in sera of 1,886 female employees of the Hospital das Clínicas, of the School of Medicine, Ribeirăo Preto, University of S. Paulo, in 1982-1983, and related to age, color, hospital unit, position and place of work, period of employment, and history of rubella or contagion when pregnant or not otherwise. In 1,617 of the 1,886 sera (85.7\%), titers (reciprocal) were $>20$, and in $269(14.3 \%) \leq 20$, distributed as follows: in $9.6 \%<10 ; 1.22 \%-10 ; 3.5 \%-20 ; 5.8 \%-40 ; 10.6 \%-80 ; 20.7 \%-160 ; 27.8 \%-320 ; 12.6 \%-640 ; 7.3 \%-1,280$ and $0.8 \%-2,560$. There was a weak association between titer and all other parameters $(P \cong 0) ; 87.1 \%$ of the employees denied a history of rubella and $73.9 \%$ of them had $>20$ titers; $57.5 \%$ denied communicant status, all also having $>20$ titers; in $1.1 \%$ of $11.1 \%$ who reported a history of rubella, titers were $\leq$ $20 ; 97 \%$ denied contact with rubella during pregnancy. There was one case of congenital malformation after rubella during the 1st trimester of pregnancy. Specific IgM was detected in $9.4 \%$ or 351 employees with $\geq 640$ titers. No significant titer fluctuation was observed in different samples of one and the same employee. It follows that most employees are immune to rubella ( $>20$ titer) regardless of the other parameters considered. The specific IgM may indicate subclinical disease or IgM persistence. The survey was considered useful for medical guidance of pregnant employees when they contacted a patient with suspected or confirmed rubella, and phrophylaxis for non-pregnant employees known to be non immune.

UNITERMS: Rubella, immunology. Health surveys. Serodiagnosis.

\section{REFERÊNCIAS BIBLIOGRÁFICAS}

1. AMARAL, E.H.C.; MARANGONI, D.B.; SOUZA, H.A. Rubeola: aspectos epidemiológicos na Guanabara. $J$. bras. Med., 21: 55-79, 1971.

2. ARCHEVAS-FERREIRA, M.E.; CARMO LAGROTA, M.H. do; MORAES ANDRADE, C. de Estudos epidemiologicos sobre rubeola. Rev. latinoamer. Microbid., 16: 143-6, 1974.

3. BANATVALA, J.E.; BEST, J.M.; KENNEDY, E.A.; SMITH, E.E.; SPENCER, M.E. A serological method for demonstrating recent infection by rubella virus. Brit. med. J., 3: 285-6, 1967.

4. BARRETO, S.M.V. Quantificaça de proteínas totais e fraçóes e imunoglobulinas: níveis no soro de reckmmascidos normais do Hospital das Clínicas de Ribeirão Prewo. Ribeiráo Preto, 1980. [Dissertaçăo de Mestrado Fecaldade de Medicina de Ribeiråo Preto da USP].

5. BAUBLIS, J.V. \& BROWN, G.C. Specific response of the imunoglobulins to rubella infection. Proc. Soc. exper. Biol. Med., 128: 206-10, 1968.
6. BIANO, S.; COCHRAN,W.; HERRMANN, K.L.; HALL, A.D.; CHANG, TE-WEN. Rubella reinfection during pregnancy: a case of mistaken diagnosis of congenital rubella. Amer. J. Dis. Child., 129: 1353- 6, 1975.

7. BIOLAB-MÉRIEUX. Diagnóstico da rubtola: teste de inibiç̃̃o da hemaglutinaçăo (microtécnica). In: BiolabMérieux. Imunologia. Rio de Janeiro, s.d. 3 p.

8. BISHOP, Y. M. M.; FIENBERG, S. E.; HOLLANDER, P. W. Mensures of association and agreement. In: Bishop, Y. M. M.; Fienberg, S. E.; Hollander, P. W. Dis. crete multivariate analysis: theory and practice. Cambridge, Mass., The Mit Press, 1980. p. 373-400.

9. BRADSTREET, P. C. M.; KIRKWOOD, B.; PATTISON, J. R.; TOBIN, J. O'H. The derivations of a minimum imune titre of rubella haemagglutinationinhibition (HI) antibody: a Public Health Laboratory Service Collaborative Survey. J. Hyg., 81: 383-8, 1978.

10. CABASSO, V. J.; LOUIE, R. E.; HOK, K. A.; ROBINSON, C. T.; DAVIS, P. C.; MINER, R. C. Loss of 
rubella antibody from immune globulin treated with kaolin. Appl. environ. Microbiol., 18: 410-5, 1969.

11. CANDEIAS, J. A. N. \& ROSENBURG, C. P. Inquérito sorológico para rubéla em professoras do município de São Paulo, Brasil. Rev. Saúde públ., S. Paulo, 8: 391-8, 1974.

12. CANDEIAS, J. A. N.; ROSENBURG, C. P.; RÁCZ, M. L. Resposta sorológica de adultos à vacinação contra a rubéola. Rev. Saúde públ., S. Paulo, 11: 345-52, 1977.

13. CENTER FOR DISEASE CONTROL. Rubella in hospital personnel and patients - Colorado. Morb. Mort. wkly Rep., 28: 325-7, 1979.

14. CENTER FOR DISEASE CONTROL. Rubella prevention. Morb. Mort. wkly Rep., 30: 37-47, 1981.

15. CLARKE, D. H. \& CASALS, J. Techniques for hemagglutination and hemagglutination-inhibition with arthropod-bome viruses. Amer. J. trop. Med., 7: 561-73, 1958.

16. CRADOCK-WATSON, J. E.; RIDEHALGH, M. K. S.; ANDERSON, M. J.; PATTISON, J. R. Outcome of asymptomatic infection with rubella virus during pregnancy. J. Hyg., 87: 147-54, 1981.

17. DAVIS, W. J.; LARSON, H. E.; SIMSARIAN, J. P.; PARKMAN, P. D.; MEYER Jr., H. M. A study of rubella immunity and resistance to infection. J. Amer. med. Ass., 215: 600-8, 1971.

18. DOWDLE, W. R.; FERREIRA, W.; SALLES GOMES, L. F. de; KING, D.; KOURANY, M.; MADALENGOITIA, J.; PEARSON, E.; SWANSTON, W. H.; TOSI, H. C.; VILCHES, A. M. WHO collaborative study on the sero-epidemiology of rubella in Caribbean and middle and South American populations in 1968. Bull. Wld Hlth Org., 42: 419-22, 1970.

19. FIELD, P. R. \& MURPHY, A. M. The role of specific IgM globulin estimations in the diagnosis of acquired rubella. Med. J. Aust., 2: 1244-8, 1972.

20. GREAVES, W. L.; ORENSTEIN, W. A.; STETLER, H. C.; PREBLUD, S. R.; HINMAN, A. R.; BART, K. J. Prevention of rubella transmission in medical facilities. J. Amer. med. Ass., 248: 861-4, 1982.

21. HOLLANDER, M. \& WOLFE, D. A. The one-sample location problem. In: Hollander, M. \& Wolfe, D.A. Non parametric statistical methods. New York, John Wiley, 1973. p. 26-66.

22. HORNSLETH, A.; LEERHOY, J; GRAUBALLE, P.; SPANGGAARD, $\mathrm{H}$. Persistence of rubella virusspecific immunoglobulin $M$ and immunoglobulin $A$ antibodies: investigation of successive serum samples with lowered immunoglobulin G concentration. Infect. Immun., 11: 804-8, 1975.

23. HORSTMANN, D. M.; BANATVALA, J. E.; RIORDAN, J. T.; PAYNE, M. C.; WHITTEMORE, R.; OPTON, E. M.; duVE FLOREY, C. Matemal rubella and the rubella syndrome in infants. Amer. J. Dis. Child., 110 $408-15,1965$
24. ISHAK, R.; LEÂO, J. E.; CARDOSO, D. D. de P.; FERNANDES, O. F. L. Prevalência de anticorpos para rubéola em um segmento da população feminina, gestante ou não, em Goiânia. Rev. Inst. Med. trop. S. Paulo, 23 $139-42,1981$.

25. IWAKATA, S.; RHODES, A. J.; LABZOFFSKY, N. A. Laboratory diagnosis of rubella virus infections. Canad. med. Ass. J., 108: 894- 905, 1973.

26. MANN, J. J.; ROSSIN, R. D.; LEHRICH, J. R.; KAS$E L, J . A$. The effect of kaolin on immunoglobulins: an improved technique to remove the nonspecific serum inhibitor of reovirus hemagglutination. J. Immunol, 98: 1136-42, 1967.

27. MANN, J. M.; PREBLUD, S. R.; HOFFMAN, R. E.; BRANDLING-BENNETT, A. D.; HINMAN, A. R.; HERRMANN, K. L. Assessing risks of rubella infection during pregnancy: a standerdized approach. J. Amer. med. Ass., 245: 1647-52, 1981.

28. MATHUR, A.; TRIPATHI, R.; CHATURVEDI, U. C.; MEHRA, P. Congenital rubella following inapparent rubella infection. Indian J. med. Res., 75: 469-73, 1982.

29. McLAUGHLIN, M. C. \& GOLD, L. H. The New York rubella incident: a case for chaging hospital policy regarding rubella testing and immunization. Amer. J. publ. Hlih, 69: 287-9, 1979.

30. MILLS, D. A.; PARKER, K. R.; EVANS, C. E. Rubella antibody titres and imunization status in a family practice. Conad. med. Ass. J., 122: 549-52, 1980.

31. MORGAN-CAPNER, P.; BURGESS, C.; IRELAND, R. M.; SHARP, J. C. Clinically apparent rubella reinfection with a detectable rubella specific IgM response. Brit. med.J., 286: 1616, 1983.

32. MORGAN-CAPNER, P.; HAMBLING, M. H.; COLEMAN, T. J.; WATKINS, R. P.; STERN, H.; HODGSON, J.; DULAKE, C.; BOSWELL, P. A.; BOOTH, J.; BEST, J. M; BANATVALA, J. E. Detection of rubella-specific IgM in subclinical rubella reinfection in pregnancy. Lancel , 1: 244-6, 1985.

33. NORTHROP, R. L.; GARDNER, W. M.; GEITTMANN, W. F. Rubella reinfection during early pregnancy: a case report. Obstet. Gynec., 39: 524-6, 1972.

34. ORENSTEIN, W. A.; HESELTINE, P. N. R.; LeGAGNOUX, S. J.; PORTNOY, B. Rubella vaccine and susceptible hospital employees. J. Amer. med. Ass., 245: $711-3,1981$.

35. PERSON, D. A. \& HERMANN Jr., E. C. Laboratory diagnosis of rubella virus infections and antibody determinations in routine medical practice. Mayo clin. Proc., 46: 477.83, 1971.

36. POLK, B. F; WHITE, J. A.; DeGIROLAMI, P. C.; MODLIN, J. F. An outbreak of rubella among hospital personnel. New Engl. J. Med., 303: 541-5, 1980.

37. PREBLUD, S. R.; SERDULA, M. K.; FRANK Jr., J. A.; BRANDLING-BENNETT, A. D.; HINMAN, A. R. Rubella vaccination in the United States: a ten-year review. Epidemiol. Rev., 2: 171-94, 1980. 
38. RAWLS, W. E.; MELNICK, J. L.; BRADSTREET, C. M. P.; BAILEY, M.; FERRIS, A. A.; LEHMANN, N. I; NAGLER, F. P.; FURESZ, J.; KONO, R.; OHTAWARA, M. ; HALONEN, P.; STEWART, J.; RYAN, J. M.; STRAUSS, J.; ZDRAZILEK, J.; LEERHOY, J.; MAGNUS, H. VON; SOHIER, R.; FERREIRA, W. WHO collaborative study on the seroepidemiology of rubella. Bull Wld Hith Org., 37: 79 . 88, 1967.

39. RUBELLA reinfection and the fetus. [Editorial]. Lancet, 1: 978, 1973.

40. SEVER, J.L. \& CLEYHORN, C. Rubella diagnostic tests: what is a significant result? Postgrad. Med., 71: 73-7, 1982.

41. STEGEL, S. Measures of correlation and their tests of significant. In: Siegel, S. Non parametric statistics for the behavioral sciences. New York, McGraw-Hill, 1956. p. 195-244.

42. SKAUG, K.; ULSTRUP, J. C.; STRAY-PEDERSEN, B. A rubella epidemic in an unvaccinated pregnant population. I. Screening methods and serological results. Scand. J. infect. Dis., 13: 11-5, 1981.

43. STEWART, G. L; PARKMAN, P. D.; HOPPS, E. H.; DOUGLAS, R. D.; HAMILTON, J. P.; MEYER, $H$. Rubella-virus hemaglutination-inhibition test. New Engl. J. Med., 276: 554-7, 1967.

44. STRASSBURG, M. A.; IMAGAWA, D. T.; FANNIN, S. L.; TURNER, J. A.; CHOW, A. W.; MURRAY, R A.; CHERRY, J. D. Rubella outbreak among hospital employees. Obstet. Gynec., 57: 283-8, 1981.
45. STURM, J. A. Rubéola no Rio de Janeiro: um estudo soro-epidemiologico por quatro anos (1973-1976) em mulheres jovens, Rev. bras. Pesq. med. biol., 13: 47. $52,1980$.

46. TRAAVIK, T.; SPANNE, O.; MENNEN, S. Rubella serology: a comparison of four methods for exclusion of non-specific serum inhibitors. J. Hy8., 86: 315-27, 1981.

47. VERONESI, R.; ZUCCAS, W. A.; ALTERIO, D. L Resultado do primeiro inquérito sorológico de rubtola em 100 crianças de uma croche de Săo Paulo. Bol. epidemiol., 1: 89-93, 1969.

48. VERONESI, R.; MOURA, R. A.; PENNA, H. A. O.; STRAUSS, A.; ZUCCAS, W. A.; ISSLER, H. Rubéla em Sao Paulo: inquéritos sorológicos em 349 indivíduos: avaliação clínico-sorológica de dois tipos de vacinas de virus atenuados. Rev. Hasp. Clin. Fac. Med. S. Paulo, 26: 65-8, 1971.

49. VESIRARI, T.; KAUPPINEN, M. A.; VAHERI, A. A two-year follow-up of rubella antibodies in a female population with special reference to reinfection. Scand. J. infect. Dis., 2: 81-5, 1970.

50. WEISS, K. E.; FALVO, C. E.; BUIMOVICI-KIEIN MAGILL, J. W.; COOPER, L. Z. Evaluation of an employee health service as a setting for a rubella screening and immunization program. Amer. J. pub. Hlth, 69: 281-3, 1979.

Recebido para publicaçåo em 20/7/1987 Reapresentado em 25/11/1987 Aprovado para publicaçáo em 1/12/1987 